Arq. Bras. Med. Vet. Zootec., v.68, n.5, p.1129-1136, 2016

\title{
Efeitos de dois protocolos de sedação sobre as variáveis bioquímicas em gatos
}

[Effects of two sedation protocols in biochemistry variables in cats]

\author{
J. Volpato ${ }^{1}$, C.R.S. Mattoso ${ }^{2}$, S.L. Beier ${ }^{2}$, M.M. Coelho ${ }^{3}$, R. Tocheto ${ }^{1}$, M.G. Ceregatti ${ }^{1}$, \\ R.R. Antunes ${ }^{3}$, Á. Costa $^{1}$, M.E. Saito ${ }^{1}$ \\ ${ }^{1}$ Universidade do Estado de Santa Catarina - Udesc - Lages, SC. \\ ${ }^{2}$ Universidade Federal de Minas Gerais - UFMG - Belo Horizonte, MG. \\ ${ }^{3}$ Médica veterinária autônoma
}

\begin{abstract}
RESUMO
A utilização de protocolos de sedação como auxílio na contenção de felinos para realização de coletas de sangue é de grande importância, porém a utilização de alguns fármacos pode alterar resultados e a interpretação deles. Por outro lado, a contenção física pode gerar intenso estresse, especialmente em felinos, o que também pode interferir nos resultados. Este estudo teve como objetivo avaliar exames de bioquímica clínica sob o uso de contenção física e química em gatos submetidos a dois protocolos de sedação. Foram utilizados 50 gatos, 26 fêmeas e 24 machos, sem raça definida, submetidos a contenção física e, imediatamente após, a dois protocolos de sedação, DB (dexmedetomidina $5 \mu \mathrm{g} / \mathrm{kg}$ e butorfanol $0,3 \mathrm{mg} / \mathrm{kg}$ ) e DBC (dexmedetomidina $5 \mu \mathrm{g} / \mathrm{kg}$, butorfanol $0,3 \mathrm{mg} / \mathrm{kg}$ e cetamina $3 \mathrm{mg} / \mathrm{kg}$ ), aplicados por via intramuscular. Amostras de sangue foram coletadas após a contenção física e, em seguida, após o uso de um dos protocolos de sedação. Foram avaliados: ureia, creatinina, alaninoaminotransferase (ALT), fosfatase alcalina, proteína sérica total (PST), albumina, globulinas, colesterol, triglicérides, cálcio, magnésio e cloretos de amostras de soro, lactato e glicose de amostras de plasma fluoretado. Foi encontrada diferença estatística entre grupos para albumina, triglicérides, PST e colesterol, com maiores valores sendo encontrados no grupo DBC. Entre momentos, houve diferença para colesterol e fosfatase alcalina, com maiores valores no momento contenção física somente no grupo DBC. Já a glicose teve maiores valores após a sedação em ambos os grupos. O estudo revelou que o uso destes protocolos implica restrições para alguns parâmetros bioquímicos aqui estudados e que suas interpretações devem ser avaliadas cuidadosamente.
\end{abstract}

Palavras-chave: felinos, contenção física, sedação, bioquímica

\begin{abstract}
The use of sedation protocols to assist in the restraint of cats to perform blood collections is of great importance, but the use of some drugs can alter the results and interpretation. Moreover, the physical restraint may generate intense stress, especially in animals of the feline species, which may also interfere with the results. This study aimed to evaluate examinations of clinical biochemistry in the use of physical restraint and chemistry in cats subjected to two sedation protocols. We used 50 cats, 26 females and 24 males, of mixed-breed, who underwent physical restraint and immediately after underwent two sedation protocols, DB (dexmedetomidine $5 \mu \mathrm{g} / \mathrm{kg}$ and $0.3 \mathrm{mg}$ butorphanol / $\mathrm{kg}$ ) and DBC (dexmedetomidine $5 \mu \mathrm{g} /$ $\mathrm{kg}$ butorphanol $0.3 \mathrm{mg} / \mathrm{kg}$ ketamine and $3 \mathrm{mg} / \mathrm{kg}$ ), applied intramuscularly. Blood samples were taken after physical restraint and then after the use of one of the sedation protocols. The following parameters were evaluated: urea, creatinine, alanine aminotransferase (ALT), alkaline phosphatase (ALP), total serum protein (TP), albumin, globulin, cholesterol, triglycerides, calcium, magnesium and chloride in serum samples, and lactate and glucose in fluoride plasma samples. Statistical difference was found between groups for albumin, triglycerides, TP and cholesterol with higher values being found in the DBC group. A statistical difference between moments was found for cholesterol, and ALP with higher values in
\end{abstract}

Recebido em 3 de agosto de 2015

Aceito em 18 de fevereiro de 2016

E-mail: jully_volps@hotmail.com 
physical restraint only in the DBC group. Glucose had greater values after sedation for both groups. The study revealed that the use of these protocols implies restrictions on some biochemical parameters studied here, and that their interpretations should be evaluated carefully.

Key words: feline, physical restraint, sedation, biochemistry

\section{INTRODUÇÃO}

A avaliação dos parâmetros bioquímicos vem se tornando parte fundamental na rotina de avaliação clínica na medicina de pequenos animais. Esses exames são comumente utilizados na pesquisa de doenças em animais aparentemente saudáveis, além de auxiliar no diagnóstico e na monitoração da progressão das enfermidades e também na resposta ao tratamento (Bartges e Osborne, 1995).

A espécie felina nem sempre se mostra confortável com a manipulação necessária para coleta de sangue e com a venopunção, fato que pode ser desagradável para o animal e para a equipe envolvida, além de interferir na obtenção de amostras de boa qualidade (Godfrey, 1997). Dessa forma, uma combinação de fármacos pode ser utilizada para facilitar a realização de procedimentos ambulatoriais como coleta de amostras de sangue, colaborando para a obtenção de resultados diagnósticos confiáveis. É importante frisar que esses fármacos devem causar o mínimo de efeitos secundários ao sistema cardiovascular e às variáveis hematológicas (Biermann et al., 2012).

Por muito tempo, os protocolos anestésicos para gatos eram inadequados, e os pacientes se recuperavam com sinais de excitação, dor ou, então, apresentavam-se muito deprimidos. Atualmente a escolha do protocolo a ser utilizado pode variar, porém existem protocolos de sedação mais eficientes e seguros, garantindo uma depressão adequada do sistema nervoso central, sem causar reações indesejadas nos animais (Tarragona et al., 2012).

A dexmedetomidina pertence ao grupo dos agonistas dos receptores $\alpha$-adrenérgicos, sendo altamente específicos para os receptores $\alpha-2$. Em gatos, promove níveis de sedação dosedependente, e a intensidade dos seus efeitos é semelhante ao obtido com o dobro da concentração de medetomidina (Plumb, 2005).
O butorfanol é um derivado sintético da morfina e possui efeitos agonista, agonista parcial e antagonista (Commiskey et al., 2005). Em gatos, promove analgesia visceral e leva a uma leve sedação quando aplicado isoladamente (Ansah $e t$ al., 2002).

A cetamina é uma droga dissociativa de rápida ação, inibidora do GABA, podendo também inibir serotonina, norepinefrina e dopamina (Plumb, 2005). Pode ser utilizada individualmente ou em combinação com outros agentes na contenção química para a realização de procedimentos diagnósticos (Perkowski, 2007).

A utilização de determinados protocolos de sedação pode levar a diversas alterações nos valores bioquímicos em gatos (Biermann et al., 2012; Reynolds et al., 2012).

Na medicina felina, nem sempre as amostras biológicas são coletadas com facilidade, principalmente por particularidades da espécie. A utilização de protocolos de sedação pode ser fundamental para a realização de diversos procedimentos ambulatoriais, mas, para obtenção de resultados fidedignos, é importante que a coleta de amostras biológicas seja realizada de forma adequada, fato que pode ser prejudicado caso não ocorra colaboração do animal. Por outro lado, esses medicamentos podem gerar alterações nos resultados obtidos. Dessa forma, o objetivo deste estudo foi avaliar os efeitos resultantes do estresse causado pela contenção física e a utilização de diferentes protocolos de sedação nos valores de bioquímica sérica em gatos. Trabalhou-se com a hipótese de que certas drogas (dexmedetomidina, butorfanol e cetamina) podem alterar os parâmetros bioquímicos séricos.

\section{MATERIAL E MÉTODOS}

Este estudo foi aprovado pelo Comitê de Ética em Experimentação Animal, CAV-UDESC, protocolo $\mathrm{n}^{\mathrm{o}}$ 1.69.12. 
Foram utilizados 50 felinos, 26 fêmeas e 24 machos, com idade entre um e sete anos e pesando $3,3 \pm 0,9 \mathrm{~kg}$. Os animais eram oriundos de proprietários que aceitaram a participação no experimento, mediante assinatura de termo de responsabilidade. Todos os animais foram recebidos um dia antes da realização do experimento e submetidos a exames prévios. Foram incluídos somente animais que não apresentaram alterações clínicas ou laboratoriais (ASA1-American Society of Anesthesiologists). Animais muito agressivos não foram utilizados neste estudo. Os animais foram submetidos a jejum de sólidos de oito horas e jejum hídrico de duas horas. No dia do estudo, foi realizada tricotomia na região do pescoço para melhor visualização das veias jugulares, e duas horas antes do início das coletas foi aplicado creme anestésico (EMLA, lidocaína e prilocaína, AstraZeneca, Brasil) na região do pescoço, para minimizar o estresse da picada da agulha.

Após a inclusão no estudo, os animais foram alocados de forma aleatória em um dos grupos experimentais. Foi padronizado o mesmo número de machos $(n=12)$ e fêmeas $(n=13)$ em cada grupo.

Foram realizados dois grupos experimentais, sendo eles: grupo DB: utilização de dexmedetomidina na dose de $5 \mu \mathrm{g} / \mathrm{kg}$ (Dexdomitor, cloridrato de dexmedetomidina, Orion Pharma, Finlândia) e butorfanol $0,3 \mathrm{mg} / \mathrm{kg}$ (Torbugesic, tartarato de butorfanol, Fort Dodge, Brasil). Os dois fármacos foram administrados em combinação na mesma seringa pela via intramuscular;

grupo DBC: utilização de dexmedetomidina $(5 \mu \mathrm{g} / \mathrm{kg})$, butorfanol $(0,3 \mathrm{mg} / \mathrm{kg})$ e cetamina $3 \mathrm{mg} / \mathrm{kg}$ (Dopalen, cloridrato de cetamina, Vetbrands, Brasil). Os três fármacos foram administrados em combinação na mesma seringa pela via intramuscular.

Os gatos foram contidos fisicamente por pessoa experiente no manuseio de felinos. Os animais foram contidos manualmente, sendo posicionados em decúbito ventral com uma leve inclinação do pescoço para minimizar o estresse agudo. Este procedimento foi realizado pela mesma pessoa durante todo o experimento. Para padronização, todos os animais utilizaram máscaras faciais. $\mathrm{O}$ grau de estresse agudo foi avaliado durante a contenção física (antes da sedação) utilizando-se um escore de estresse, que foi desenvolvido em estudo piloto anterior (Tab. $1)$.

Tabela 1. Escala utilizada para avaliação de estresse agudo em gatos durante a contenção física

\begin{tabular}{ccl}
\hline Pontuação & Grau & \multicolumn{2}{c}{ Alterações encontradas } \\
\hline 0 & Nenhum estresse & Não houve demonstração de resistência à contenção física. \\
\hline 1 & Estresse discreto & $\begin{array}{l}\text { Houve discreta resistência à contenção física, demonstrou } \\
\text { movimentação, ou se mostrou ansioso, mas sem comprometer a } \\
\text { coleta de sangue. }\end{array}$ \\
\hline Estresse & $\begin{array}{l}\text { Houve moderada resistência à contenção física, apresentou } \\
\text { movimentos constantes, mas não vigorosos, mostrou-se ansioso e } \\
\text { apresentou vocalização ao ser contido. Essas alterações } \\
\text { comprometeram e dificultaram a coleta de sangue. }\end{array}$ \\
\hline 3 & Estresse intenso & $\begin{array}{l}\text { Houve intensa resistência à contenção física, apresentou } \\
\text { movimentos constantes e vigorosos, mostrou-se ansioso e } \\
\text { apresentou vocalização ao ser contido. Ainda, pode ter se tornado } \\
\text { agressivo (morder e arranhar) e urinado ou defecado durante a } \\
\text { contenção. Essas alterações comprometeram e dificultaram a coleta } \\
\text { de sangue. }\end{array}$ \\
\hline
\end{tabular}

Fonte: Volpato et al., 2015.

As amostras de sangue foram coletadas em dois momentos. A primeira amostra foi coletada com o animal sob contenção física (venopunção jugular direita). Nesse momento, foi realizado o menor número de punções possível para a obtenção da quantidade de amostra necessária para a realização dos testes laboratoriais. Logo após a coleta de amostra sob contenção física, o animal foi submetido à contenção química, com a aplicação de um dos protocolos de sedação, e 
então procedeu-se à coleta da segunda amostra, que foi realizada após contenção química por um dos protocolos experimentais (venopunção jugular esquerda). As amostras só eram coletadas após constatação do efeito da sedação. Novamente, foi realizado o menor número de punções possível para a obtenção da quantidade de amostra necessária para a realização dos testes laboratoriais.

Aproximadamente $6 \mathrm{~mL}$ de sangue foram coletados em cada momento. Para a coleta das amostras de sangue, foram utilizadas agulhas $0,55 \times 20 \mathrm{~mm}$ (Descarpack, Brasil), e seringas de 3 e $5 \mathrm{~mL}$ (Descarpack, Brasil). Aproximadamente $1 \mathrm{~mL}$ de sangue foi acondicionado em microtubos, preparados com fluoreto de sódio na proporção de $20 \mu \mathrm{L}$ para cada $1 \mathrm{~mL}$, para a dosagem de lactato e glicose. E aproximadamente $5 \mathrm{~mL}$ de sangue foram acondicionados em tubos sem anticoagulante (Descarpack, Brasil) para realização das demais dosagens bioquímicas. As amostras de sangue foram centrifugadas a $165 \mathrm{~g}$ por 10 minutos, para obtenção de plasma fluoretado e soro, acondicionadas em microtubos de polipropileno e armazenadas a $-20^{\circ} \mathrm{C}$ até o momento do processamento.

O plasma fluoretado foi utilizado apenas para realização das dosagens de lactato e glicose. Já o soro foi utilizado para as seguintes dosagens: ureia, creatinina, alanino aminotransferase (ALT), fosfatase alcalina (FA), proteína sérica total (PST), albumina, globulinas, colesterol, triglicérides, cálcio, magnésio e cloretos. Todas as dosagens foram realizadas com auxílio de kits comerciais (Labtest, Brasil), utilizando-se o analisador bioquímico semiautomático (TP Analyzer Plus ${ }^{\circledR}$, Thermo Plate, Brasil).

Todos os dados foram analisados com auxílio do programa computacional Sigma Stat (Windows). A normalidade foi testada pelo teste de ShapiroWilk, e alguns dados não apresentaram distribuição normal (ureia, magnésio, proteína sérica total, albumina, globulinas e triglicérides). Os valores encontrados foram comparados entre grupos e entre momentos. As variáveis que apresentaram distribuição normal foram avaliadas pelo teste $\mathrm{t}$ pareado e as variáveis que não apresentaram distribuição normal foram avaliadas pelo teste de Wilcoxon. As diferenças foram consideradas estatisticamente significativas quando $\mathrm{P} \leq 0,05$.

\section{RESULTADOS}

Os dois protocolos estudados (DB e DBC) forneceram sedação adequada para a realização da coleta de amostras de sangue, com sedação moderada a intensa na maioria dos animais. $\mathrm{O}$ período para início da sedação não foi muito longo (11 a 12 minutos), com duração suficiente para realização da coleta de amostras de sangue (DB: 17 minutos e DBC: 31 minutos). Os dados relacionados à sedação foram publicados anteriormente (Volpato et al., 2015).

A avaliação do estresse revelou que os animais do grupo DB apresentaram maior grau de estresse: $52 \%$ (13/25) dos gatos do grupo DB apresentaram graus 2 ou 3 na escala de estresse (estresse moderado a intenso), enquanto $76 \%$ $(19 / 25)$ dos gatos do grupo DBC apresentaram graus 0 ou 1 na escala de estresse (estresse ausente ou discreto). Entretanto, não foram encontradas diferenças estatísticas entre grupos.

Foram encontradas diferenças estatísticas entre os momentos contenção física e contenção química para número de punções no grupo DB, sendo necessário um maior número de punções no momento da contenção física (mediana 3; variação 1-4) em comparação com a contenção química (mediana 2; variação 2-4). O grupo DBC não apresentou diferenças estatísticas entre os momentos contenção física (mediana 2; variação 2-6) e contenção química (mediana 2; variação 2-4) para o número de punções. Além disso, o número de punções não diferiu entre grupos (DB e DBC) no momento contenção química.

As dosagens bioquímicas obtidas estão apresentadas na Tab. 2. Não foram encontradas diferenças estatísticas entre grupos ou momentos para a maioria das variáveis estudadas (ureia, creatinina, ALT, lactato, cálcio, magnésio, cloretos e globulinas). 
Efeitos de dois...

Tabela 2. Dosagens bioquímicas séricas (média+DP) de felinos $(\mathrm{n}=50)$ nos grupos e momentos estudados

\begin{tabular}{lccccc}
\multicolumn{5}{c}{ Variável } & \multicolumn{2}{c}{ DBé } & Pós & Pré & Pós & Referência $^{1}$ \\
\hline Albumina (g/dL) & $2,42 \pm 0,39 \mathrm{~A}$ & $2,32 \pm 0,39 \mathrm{~A}$ & $2,72 \pm 0,50 \mathrm{~B}$ & $2,68+0,63 \mathrm{~B}$ & $2,1-3,3$ \\
ALT (U/L) & $27,17 \pm 13,05$ & $25,24 \pm 11,19$ & $34,53 \pm 27,52$ & $31,56+32,72$ & $6,0-83,0$ \\
Cálcio (mg/dL) & $9,32 \pm 2,76$ & $9,35 \pm 2,52$ & $8,54 \pm 2,61$ & $8,28+2,93$ & $6,2-10,2$ \\
Cloreto (mg/dL) & $118,17 \pm 12,39$ & $122,38 \pm 18,13$ & $126,84 \pm 13,86$ & $121,31+13,33$ & $95,0-130,0$ \\
Colesterol (mg/dL) & $102,91 \pm 41,07 \mathrm{~A}$ & $89,47 \pm 23,98 \mathrm{~A}$ & $139,15 \pm 56,01 \mathrm{aB}$ & $127,63+49,56 \mathrm{bB}$ & $95,0-130,0$ \\
Creatinina (mg/dL) & $1,39 \pm 0,38$ & $1,35 \pm 0,39$ & $1,30 \pm 0,27$ & $1,33+0,40$ & $0,8-1,8$ \\
FA (U/L) & $50,26 \pm 26,90$ & $45,59 \pm 21,02$ & $62,20 \pm 33,27 \mathrm{a}$ & $51,21+25,48 \mathrm{~b}$ & $25,0-93,0$ \\
Glicose (mg/dL)* & $98,55 \pm 28,21 \mathrm{a}$ & $122,31 \pm 40,76 \mathrm{~b}$ & $93,71 \pm 23,15 \mathrm{a}$ & $127,80+46,64 \mathrm{~b}$ & $73,0-134,0$ \\
Globulinas (g/dL) & $3,97 \pm 1,67$ & $4,42 \pm 0,85$ & $5,23 \pm 1,06$ & $4,58+1,70$ & $2,6-5,1$ \\
Lactato (mg/dL)* & $28,26 \pm 7,53$ & $25,79 \pm 9,84$ & $28,73 \pm 10,28$ & $26,60+12,17$ & - \\
Magnésio (mg/dL) & $2,29 \pm 0,54$ & $2,38 \pm 0,35$ & $2,26 \pm 0,38$ & $2,21+0,44$ & $1,94-2,67^{2}$ \\
PST (g/dL) & $6,63 \pm 1,17 \mathrm{~A}$ & $6,74 \pm 0,87 \mathrm{~A}$ & $7,94 \pm 1,26 \mathrm{~B}$ & $7,25+1,69 \mathrm{~B}$ & $5,4-7,8$ \\
Triglicérides (mg/dL) & $44,46 \pm 24,06 \mathrm{~A}$ & $47,10 \pm 27,79 \mathrm{~A}$ & $70,64 \pm 15,66 \mathrm{~B}$ & $66,69+13,48 \mathrm{~B}$ & $10,0-114,0$ \\
Ureia (mg/dL) & $48,84 \pm 13,50$ & $51,51 \pm 15,86$ & $48,69 \pm 14,48$ & $48,27+12,12$ & $42,8-64,2$ \\
\hline
\end{tabular}

ALT (alaninoaminotransferase); FA (fosfatase alcalina); PST (proteína sérica total).

* Dosagem realizada em plasma de fluoreto.

${ }^{\mathrm{ab}}$ Letras minúsculas diferentes indicam diferença estatística entre momentos.

${ }^{\mathrm{AB}}$ Letras maiúsculas diferentes indicam diferença estatística entre grupos.

${ }^{1}$ Kaneko et al., 2008.

${ }^{2}$ Reynolds et al., 2012.

Foram encontradas diferenças estatísticas entre grupos para albumina $(\mathrm{P}=0,017)$, triglicérides $(\mathrm{P}=0,008), \quad \mathrm{PST} \quad(\mathrm{P}=0,017) \quad$ e colesterol $(\mathrm{P}=0,002)$, com maiores valores sendo observados no grupo DBC.

Foram encontradas diferenças estatísticas entre momentos para colesterol $(\mathrm{P}<0,001)$ e FA $(\mathrm{P}=0,007)$, com maiores valores sendo observados no momento contenção física no grupo DBC e glicose, com maiores valores sendo encontrados no momento contenção química em ambos os grupos DB $(\mathrm{P}=0,017)$ e $\mathrm{DBC}$ $(\mathrm{P}<0,001)$.

\section{DISCUSSÃO}

O uso de fármacos para promover sedação pode ser fundamental, principalmente naqueles pacientes que não cooperam com a manipulação necessária para procedimentos cotidianos. Com o protocolo de sedação, busca-se tranquilidade do animal e também da equipe envolvida. Com a cooperação do animal, a coleta se torna mais tranquila, eliminando o estresse como possível responsável por alterações dos exames laboratoriais, porém é importante frisar que o uso dos fármacos não deve influenciar nos resultados obtidos. Segundo Lassen (2007), a ação de catecolaminas secundárias ao estresse, dor ou exercício físico podem gerar alterações laboratoriais; por outro lado, alguns fármacos utilizados para sedação também podem ocasionar alteração nos resultados laboratoriais obtidos (Biermann et al., 2012).

O período para início da sedação foi semelhante nos dois grupos e pode ser considerado um período aceitável para a contenção química nas clínicas veterinárias, bem como o tempo de duração dessa sedação. $\mathrm{O}$ aumento significativo do tempo de duração da sedação em DBC comparado com DB ocorreu devido à ação da cetamina, que pode potencializar a ação de certos alfa 2 agonistas (Hatschbach et al., 2005).

O estresse agudo não gerou alterações nos resultados obtidos, porém, se fossem utilizados gatos agressivos, essas alterações poderiam aparecer.

Os protocolos utilizados não influenciaram na maioria dos metabólitos e enzimas avaliados neste estudo. Pode-se fazer essa afirmação pela ausência de diferenças estatísticas entre momentos e também grupos para as seguintes variáveis: ureia, creatinina, ALT, globulinas, lactato, cálcio, magnésio e cloretos. Estas variáveis também permaneceram dentro dos valores de normalidade consultados (Kaneko et $a l ., 2008)$, mostrando que a contenção física e o estresse que alguns animais sofreram durante 
imobilização, posicionamento e coleta de amostras não foram capazes de alterar esses exames.

A dosagem de albumina e, consequentemente, de PST apresentou diferença estatística entre grupos, sendo maior no grupo DBC nos dois momentos estudados (contenção física $\mathrm{e}$ contenção química). Segundo Bennett et al. (1992) a utilização de cetamina na dose de 5$10 \mathrm{mg} / \mathrm{kg}$ gera alterações nos valores dos exames laboratoriais em macacos (Macaca mulata), porém, no estudo de Bennet, encontrou-se diminuição de albumina com a utilização de cetamina, fato que não ocorreu na presente pesquisa, pois o grupo DBC apresentou valores mais elevados de albumina em relação ao DB. Ainda de acordo com Bennett et al. (1992) a diminuição da albumina ocorre após a utilização de cetamina por maior influxo de fluidos para o espaço vascular. Apesar de não existirem diferenças estatísticas, observou-se uma leve diminuição entre momentos no grupo DBC para albumina e PST, fato que poderia estar sendo causado pela diluição do sangue devido ao deslocamento de líquido para o interior dos vasos. As diferenças entre grupos encontradas na dosagem de albumina e na de PST do presente estudo ocorreram nos dois momentos estudados, ou seja, já existiam diferenças estatísticas antes da aplicação dos fármacos (momento contenção física). Dessa forma, pode-se considerar que essas diferenças ocorreram por variações individuais dos animais estudados, não apresentando relevância clínica. A diminuição da albumina após a aplicação de um protocolo envolvendo cetamina $(10 \mathrm{mg} / \mathrm{kg})$ também foi observada por Freitas et al. (2012), na espécie felina, e por Venkatesan et al. (2006), em primatas (Macaca radiata), com dose de $15 \mathrm{mg} / \mathrm{kg}$. A dose utilizada no presente estudo $(3 \mathrm{mg} / \mathrm{kg})$, sendo inferior aos estudos abordados acima, pode não ter sido suficiente para gerar deslocamento de líquidos para o espaço intravascular e consequente diminuição dos valores de PST e albumina.

A dosagem de FA apresentou diferença estatística entre momentos no grupo $\mathrm{DBC}$, tendo maiores valores no momento contenção física, o que contraria os resultados encontrados por Lin (2007) que avaliou um aumento significativo nos valores de enzimas hepáticas (ALT e FA) em humanos, porém após infusão contínua de cetamina, fato também encontrado por Fantoni et al. (1999) em cães. Como não houve diferença estatística entre grupos e os valores se mantiveram dentro dos valores de referência, provavelmente esta diferença se deve a uma variação individual entre os animais deste grupo.

Os níveis de colesterol sérico demonstraram diferenças estatísticas entre momentos no grupo $\mathrm{DBC}$, sendo encontrados menores valores no momento contenção química. Resultados semelhantes foram observados por Reynolds et al. (2012), que observaram uma diminuição nos valores de colesterol em gatos após a aplicação de cetamina $(10 \mathrm{mg} / \mathrm{kg})$ e diazepam $(0,5 \mathrm{mg} / \mathrm{kg})$. A aplicação de cetamina diminui as concentrações de colesterol e potássio (Venkatesan et al., 2006). Porém, segundo Rovirosa-Hernandez et al. (2011), ocorre aumento na concentração de colesterol induzido pela utilização de cetamina $(10-15 \mathrm{mg} / \mathrm{kg}) \mathrm{em}$ primatas (Alouatta pigra). Existe conflito de resultados sobre esse tipo de alteração, portanto novos estudos devem ser realizados. Além disso, houve também diferença estatística entre grupos, sendo os maiores valores encontrados no grupo DBC em relação ao DB, contudo essa diferença foi observada já no momento contenção física, antes mesmo da aplicação dos fármacos, o que também pode ser atribuído a uma variação individual. A dosagem de triglicérides apresentou diferenças estatísticas entre grupos, sendo maior no grupo DBC em ambos os momentos estudados. A utilização da cetamina pode justificar esse aumento no momento contenção química (Rovirosa-Hernandez et al., 2011). Já Kim et al. (2005) encontraram resultados diferentes em machos da espécie Macaca fascicularis que foram anestesiados com cetamina $(10 \mathrm{mg} / \mathrm{dL})$; onde, os valores de triglicérides foram menores após o uso da cetamina. Porém, a diferença no presente estudo, para a concentração de triglicérides, já ocorreu no momento contenção física (anterior à aplicação dos protocolos anestésicos). Dessa forma, de maneira similar ao que aconteceu para concentração de albumina, pode ter ocorrido uma provável variação individual.

A concentração de glicose apresentou diferenças estatísticas entre momentos nos dois grupos estudados (DB e DBC), apresentando maiores valores no momento contenção química. Esse fato se deve provavelmente à ação da 
dexmedetomidina, um $\alpha 2$ agonista, que realiza inibição na secreção de insulina pela ligação aos receptores alfa 2 nas células $\beta$ do pâncreas (Kanda e Hikasa, 2008). Outro estudo (Biermann et al., 2012), que avaliou gatos sob o uso de diversos protocolos, também encontrou aumento na concentração de glicose após aplicação de protocolos que incluíam dexmedetomidina $(5 \mu \mathrm{g} / \mathrm{kg})$. Maiores valores de glicose também foram encontrados por Pypendop et al. (2011) em gatos após anestesia com dexmedetomidina e isoflurano. Esses estudos corroboram os achados obtidos na presente pesquisa. Apesar desse aumento induzido pela ação da dexmedetomidina, apenas a utilização de contenção física, principalmente em animais indóceis, também pode gerar um aumento na concentração de glicose por ação das catecolaminas. As catecolaminas estimulam a glicogenólise e promovem a liberação de hormônio de crescimento (MacMahon et al., 2001), que interfere nos receptores de glicose em miócitos e adipóitos. $\mathrm{O}$ estímulo alfa 2 adrenérgico nas células beta do pâncreas diminui a liberação de insulina e a consequente utilização de glicose pelos hepatócitos, miócitos e adipócitos (Labrie et al., 1984). A falta de diferença estatística entre grupos para glicose mostra que, mesmo no grupo DB, que apresentou maior grau de estresse e número de punções, não ocorreu potencialização ao efeito hiperglicemiante da dexmedetomidina.

\section{CONCLUSÃO}

As variáveis bioquímicas sofreram algumas alterações após aplicação dos protocolos anestésicos estudados, sobretudo na avaliação do colesterol e da glicose. Essas alterações podem dificultar a interpretação desses resultados. Quando a opção da sedação/anestesia do paciente felino for considerada, a avaliação laboratorial deve ser cautelosa para evitar diagnósticos equivocados, apesar de o estresse da contenção física também poder alterar alguns resultados laboratoriais. Acredita-se que, em gatos agressivos, o uso dos protocolos estudados é indicado, principalmente para melhor manuseio do animal e consequente obtenção de amostras.

\section{REFERÊNCIAS}

ANSAH, O.B.; VAINIO, O.; HELLSTEN, C. et al. Postoperative pain control in cats: clinical trials with medetomidine and butorphanol. Vet. Surg., v.31, p.99-103, 2002.

BARTGES, J.; OSBORNE, C. Influence of fasting and eating on laboratory values. In: BONAGURA, J.D.; KIRK, R.W (Eds.). Kirk's current veterinary therapy XII. Philadelphia: WB Saunders, 1995. p.20-23.

BENNETT, J.S.; GOSSETT, K.A.; McCARTHY, M.P.; et al. Effect of ketamine hydrochloride on serum biochemical and hematologic variables in rhesus monkeys. Vet. Clin. Pathol., v.21, p.15-18, 1992.

BIERMANN, K.; HUNGERBÜHLER, S.; MISCHKE, R. et al. Sedative, cardiovascular, haematologic and biochemical effects of four different drug combinations administered intramuscularly in cats. Vet. Anaesth. Analg., v.39, p.137-150, 2012.

COMMISKEY, S.; FAN, L.W.; HO, I.K. et al. Butorphanol: effects of a prototypical agonistantagonist analgesic on kappa-opioid receptors. J. Pharmacol. Sci., v.98, p.109-116, 2005.

FANTONI, D.; CORTOPASSI, S.R.G.; BERNARDI, M.M. Anestésicos intravenosos e outros parenterais. In: SPINOSA, A.S.; GÓRNIAK, S.L.; BERNARDI, M.M. Farmacologia aplicada a medicina veterinária. 2.ed. Rio de Janeiro: Guanabara Koogan, 1999. p.114-124.

FREITAS, G.C.; CUNHA, M.G.C.M.; GOMES, $\mathrm{K}$. Acid-base and biochemical stabilization and quality of recovery in male cats with urethral obstruction and anesthetized with propofol or a combination of ketamine and diazepam. Can. J. Vet. Res., v.76, p.201-208, 2012.

GODFREY, D.R. Bronchial rupture and fatal tension pneumothorax following routine venipuncture in a kitten. J. Am. Anim. Hosp. Assoc., v.33, p.260-263, 1997.

HATSCHBACH, E.; MASSONE, F.; BECHARA, J.N. et al. Parametric evaluation of dexmedetomidine in dogs premedicated or not with atropine and treated or not with ketamine. Ars Vet., v.21, p.22-29, 2005. 
KANDA, T.; HIKASA, Y. Neurohormonal and metabolic effects of medetomidine compared with xylazine in healthy cats. Can. J. Vet. Res., v.72, p.278-286, 2008.

KANEKO, J.J.; HARVEY, J.W. Clinical biochemistry of domestic animals. 6.ed. California: Academic Press, 2008. 916p.

KIM, C.Y.; LEE, H.S.; HAN, S.C. et al. Hematological and serum biochemical values in cynomolgus monkeys anesthetized with ketamine hydrochloride. J. Med. Primatol., v.34, p.96-100, 2005.

LABRIE, F.; GIGUERE, V.; PROULX, L. et al. Interactions between CRF, epinephrine, vasopressin and glucocorticoids in the control of ACTH secretion. J. Steroid Biochem., v.20, p.153-160, 1984.

LASSEN, E.D. Avaliação laboratorial do pâncreas endócrino e do metabolismo da glicose. In: THRALL, M.A.; BAKER, D.C.; CAMPBELL, T.W. et al. (Eds.). Hematologia e bioquímica clínica veterinária. São Paulo: Roca, 2007. p.403-415.

MACMAHON, C.D.; RADCLIFF, R.P.; LOOKINGLAND, K.J. et al. Neurorregulation of growth hormony secretion in domestic animals. Domest. Anim. Endocrinol., v.20, p.6587, 2001.

PERKOWSKI, S.Z. Pros and cons of medetomidine as part of the anesthetic protocol. In: NORTH AMERICAN VETERINARY CONFERENCE, 2007. Proceedings... Available in: <http://www.ivis.org/proceedings/navc/2007/ SAE/027.asp?LA=1>. Accessed in: 10 jul.2015.
PLUMB, D.C. Plumb's veterinary drugs handbook. 5.ed. Cambridge: Blackwell Publishing, 2005. 929p.

PYPENDOP, B.H.; BARTER, L.S.; STANLEY, S.D. et al. Hemodynamic effects of dexmedetomidine in isoflurane-anesthetized cats. Vet. Anaesth. Analg., v.38, p.555-567, 2011.

REYNOLDS, B.S.; GEFFRÉ, A.; BOURGÈSABELLA, N.H. et al. Effects of intravenous, low-dose ketamine-diazepam sedation on the results of haematologic, plasma biochemical, and coagulation analyses in cats. J. Am. Vet. Med. Assoc., v.240, p.287-293, 2012.

ROVIROSA-HERNÁNDEZ, M.J, GARCÍAORDUÑA, F., CABA, M. et al. Blood parameters are little affected by time of sampling after the application of ketamine in black howler monkeys (Alouatta pigra). J. Med. Primatol., v.40, p.294-299, 2011.

TARRAGONA, L.; CEBALLOS, M.; FUENSALIDA, S. et al. Combinación de romifidina-dextropropoxifeno y romifidinatramadol a distintas dosis, como protocolo de premadicación em felinos. J. Latinoam. Med. Vet. Emerg. Cuidados Intens., p.144-147, 2012.

VENKATESAN, R.; NAGARAJAN, P.; RAJARETNAM, R.S. et al. Hematologic and serum biochemical values in aged female bonnet macaques (Macaca radiata) anesthetized with ketamine hydrochloride. Am. Assoc. Lab. Anim. Sci., v.45, p.45-48, 2006.

VOLPATO, J.; MATTOSO, C.; BEIER, S. et al. Sedative, hematologic and hemostatic effects of dexmedetomidine-butorphanol alone or in combination with ketamine in cats. J. Feline Med. Surg., v.6, p.500-506, 2015. 